\title{
SECURE ATTACHMENT (KELEKATAN AMAN) IBU DAN ANAK DENGAN PERKEMBANGAN SOSIAL EMOSIONAL PADA ANAK
}

\author{
Vinny Arianda1, Irma Kusuma Salim², Raihanatu Binqalbi Ruzain ${ }^{3}$ \\ 1, 2, 3 Fakultas Psikologi, Universitas Islam Riau, Indonesia. \\ ${ }^{2}$ Corresponding author: irma.kusumasalim@psy.uir.ac.id
}

\begin{abstract}
This study was conducted to determine whether or not there is a relationship between secure attachment between mother and child and social emotional development. One of the factors that play a major role in the social and emotional development of children is secure attachment. This study uses a correlational quantitative method with a side technique, namely purposive sample with the number of subjects as many as 97 students' guardians (especially mothers) at RA Aisyah IT Pekanbaru. The results of the correlation test between the secure attachment variable and social emotional development using Pearson product moment analysis showed a probability number (sig 2-tailed) $0.001 \quad(p<0.005)$ which indicated that the two variables had a significant positive relationship with a correlation value of 0.332. This means that the higher the secure attachment, the higher the social-emotional development, and conversely, the lower the secure attachment, the lower the social- emotional development.
\end{abstract}

Keywords: Secure Attachment, mother, child, emotional social development

\begin{abstract}
ABSTRAK
Penelitian ini dilakukan untuk mengetahui apakah ada atau tidaknya hubungan antara secure attachment (kelekatan aman) antar ibu dan anak dengan perkembangan sosial emosional. Salah satu faktor yang berperan besar bagi perkembangan sosial emosional pada anak ialah secure attachment. Penelitian ini menggunakan metode kuantitatif korelasional dengan teknik samping yaitu purposive sample dengan jumlah subjek sebanyak 97 orang wali murid (khusus ibu) di RA Aisyah IT Pekanbaru. Hasil uji korelasi antara variabel secure attachment dengan perkembangan sosial emosional menggunakan analisis pearson product moment menunjukkan angka probabilitas (sig 2-tailed) 0,001 $(p<0,005)$ yang menunjukkan bahwa kedua variabel memiliki hubungan positif signifikan dengan nilai korelasi 0,332. Maknanya, semakin tinggi secure attachment maka akan semakin tinggi pula perkembangan sosial emosional dan sebaliknya semakin rendah secure attachment maka akan semakin rendah pula perkembangan sosial emosional.
\end{abstract}

Kata kunci: Secure Attachment, Ibu, Anak, Perkembangan Sosial Emosional

\section{PENDAHULUAN}

Golden Age (usia emas) seorang anak merupakan tahapan penting pertumbuhan dan perkembangan seorang anak, hal ini akan menentukan tahapan pertumbuhan dan perkembangan berikutnya. Sebagian besar pertumbuhan dan perkembangannya terjadi dan akan terjadi berupa perkembangan sosial, emosional, verbal, kognitif, fisiologis, dan motorik. Salah satu aspek perkembangan anak yang terpenting adalah aspek perkembangan masyarakat. Keluarga, teman sebaya, masyarakat dan lingkungan sekolah memegang peranan penting dalam pembentukan karakter anak. (Lubis, 2019).

Tidak banyak orang tua yang memahami pentingnya contoh perilaku 
yang diberikannya kepada anaknya, yang nantinya berpengaruh pada tumbuh kembang anaknya. Mereka percaya bahwa ketika seorang anak pergi ke sekolah, perkembangan anak secara alami tumbuh dengan baik. Teapi tidak, anak-anak yang berkembang dengan baik secara alami sangat dipengaruhi oleh keluarga( orang tua) karena mereka adalah orang pertama yang bertindak sebagai panutan dan panutan bagi anak-anaknya. (Lubis, 2019).

Terkait dengan pembahasan materi tentang anak, dalam UU Negara Indonesia dengan nomor 20 pada tahun 2003, pemerintah menetapkan sistem pendidikan yang harus dipatuhi oleh seluruh rakyat Indonesia yaitu (Permendiknas Nomor 58, 2009: 1). Jika kita artikan, hal ini memiliki makna peraturan pemerintah bertujuan untuk mencegah serta menghindari sikap menyimpang yang mungkin akan terjadi pada anak jika tidak diberi pengertian sejak dini.

Hal ini setara dengan Erikson (dalam Santrock, 2007) tahun-tahun awal kehidupan itu ialah komponen yang harus kita miliki ketika membentuk pola attachment ini, karena pada tahun-tahun awal kita hidup adalah jenjang untuk timbulnya rasa percaya dan tidak percaya. Tahun-tahun awal kehidupan sang anak juga kerap disebut dengan "golden age" yang hanya datang sekali saja, pada saat inilah ibu hendaknya secara aktif memberi rangsangan dan stimulus agar perkembangan anak berlangsung secara optimal dengan berbagai hal, mulai dari yang sederhana yaitu mengajak anak bercerita, mendengarkan keluh kesah anak, memenuhi kebutuhan sang anak, sehingga terjalin rasa percaya dan rasa aman dari sang anak kepada ibunya. Riset menunjukkan bahwa pertumbuhan otak anak yang jarang diberi sentuhan kehangatan, rangsangan secara visual dan verbal maupun taktil dan kinestetik akan mengalami perkembangan sebanyak $20 \%$ hingga 30\% lebih sedikit disbanding teman sebayanya (Mutiah, 2012).

Adanya kekerasan dan pelecehan seksual terhadap anak yang terjadidewasa ini menjadi peringatan bagi orang tua akan pentingnya menjaga agar anak terhindar dari perilaku yang tidak senonoh tersebut. Cnn (2021) berdasarkan data yang bersumber dari kemenpppa, pada tahun 2019 tercatat setidaknya sebanyak 11.057 kasus kekerasan, 11.279 kasus pada tahun 2020, dan sangat meningkat pesat di tahun 2021 yaitu sebanyak 12.566 kasus terhitung hingga november 2021. Kasus yang paling banyak dialami oleh anak ialah kekerasan seksual yaitu sebesar $45 \%$, sedangkan kekerasan psikis sebesar 19\%, dan kekerasan fisik sekitar $18 \%$.

Kasus pelecehan seksual pada anak kian marak, diberitakan seorang guru dan pemilik pondok pesantren memperkosa 12 orang santriwati, bahkan 8 diantaranya dikabarkan sudah melahirkan. kemudian terungkap pula bahwa seorang guru agama mencabuli 15 siswi SD di Cilacap, Jawa Tengah. hal ini mengakibatkan anak mengalami kondisi terguncang setelah mengalami hal yang mengerikan, menurut psikolog anak dan keluargabernama Anna Surti Ariani, S.Psi., M.Psi tak jarang anak yang menjadi korban pelecehan seksual disalahkan, baik itu dari orang tua, keluarga, maupun orang lain. (Kompas.com, 2021).

Berdasarkan kasus tersebut, sangat disayangkan bahwa anak-anak yang mengalami kejadian mengerikan itu sering kali tidak dirangkul oleh orang terdekat bahkan orang tuanya sendiri, ini bisa saja berdampak pada hubungan antara orang tua dan anak, anak akan merasa bahwa orang tuanyatidak bisa dipercaya dan tidak bisa memberikan rasa aman lagi, anak akan tumbuh menjadi individu yang menolak akan kehadiran orang tuanya. 
Anak yang memiliki Secure Attachment, akan memiliki ibu yang responsif dan selalu memberi timbal balik pada anaknya yang bersifat konsisten (bertahandalam jangka waktu yang lama). Sedangkan anak yang Ambivalent adalah cerminan dari individu yang kesulitan untuk bersosialisasi dengan lingkungan sekitarnya, bisa saja hal ini diakibatkan oleh respon atau ketersediaan yang tidak konsisten untuk memberi timbal balik pada anak sebagai orang tua maupun pengasuhnya. Pada akhirnya hubungan kelekatan yang ingin dicapai tidak terpenuhi.

Hal ini juga sebutkan pada hasil penelitian oleh Voort dkk (dalam Akmalia \& Rahayuningsih, 2018). Dari 456 responden diketahui cara pengasuhan yang peka / sensitif amat diperlukan untuk fondasi pertumbuhan secure attachment (kelekatan aman). Namun bagi kanak-kanak yang tersiksa mempunyai resiko cukup besar akan pertumbuhan pola insecure attachment (kelekatan tidak aman). Dari 80 orang sampel penelitian, diketahui anak dalam pola secure attachment mempunyai interaksi sosial dengan baik terhadap anak lain seusianya, namun anak dengan pola insecure attachment mempunyai interaksi sosial kurang baik terhadap anak lain seusianya.

Dibandingkan dengan anggota keluarga yang lain, ibu merupakan figur lekat utama bagi anak karena ibu lah yang lebih sering menghabiskan waktu bersama anak, mulai dari berinteraksi, mengobrol, membimbing dan mengajak anak bermain, serta memastikan anak selalu merasa aman. Keberlangsungan perkembangan pada anak sangat bergantung pada ibu selaku orang yang berperan sebagai pemberi secure attachment (kelekatan aman) pada anak (Eliasa, 2011). Penemuan dari beberapa penelitian terdahulu mengungkapkan bahwa kelekatan antara anak dan orang tua terutama ibu, dapat mempengaruhi kemampuan anak untuk melakukan sesuatu serta kemampuan bersikap. Maka dari itu, attachment adalah bentuk khusus dari ikatan emosional yang menguntungkan satu sama lain (mutualisme), yang melibatkan kenyamanan, kesenangan, dan keamanan

Weingraten serta Chisholm (dalam Hewi, 2020) mengemukakan ibu adalah tempat aman dimana bayi bisa mencari kenyamanan dan keamanan, berlindung terhadap ancaman serta marabahaya, serta lingkungan yang aman bagi anak untuk melakukan mengeksplorasi, dengan harapan ibu akan selalu ada dimanapun dan kapanpun ketika anak membutuhkannya. Attachment bersifat selektif, anak biasanya memilih ibu sebagai tokoh primer, namun beberapa anak menambahkan ayah, kakak, atau pengasuh lainnnya sebagai figur lekatnya.

Yusuf (dalam suryana, 2016) mendefinisikan perkembangan sosial sebagai suatu pencapaian kematangan ketika kita bersosialisasi dengan lingkungan sosial. Perkembangan sosial juga bisa dipahami dengan prosedur memulai penyesuaian diri kepada aturanaturan kelompok, attitude, serta tradisi, sehingga kemudian kita bisa berbaur dan manjalin komunikasi serta team work.

Elizabeth b. Hurlock (dalam suyadi, 2010) memberi pendapatnya tentang perkembangan sosial yang diartikan sebagai keberhasilan kemampuan seseorang dalam bererilaku sebagaimana norma sosial yang ditegakkan serta dapat menjadi orang yang bisa bermasyarakat.

Pendapat lain mengatakan bahwa perkembangan sosial merupakan tingkatan hubungan bersosialisasi anak dengan individu lain, bermula sedari lingkungan terdekatnya yaitu ayah, ibu, kakak, adik, teman sebaya hingga orang dewasa lainnya (Jahja, 2011). Lewat relasi serta jalinan sosial, mau itu dengan lingkukan 
keluarga maupun lingkungan luar, perilaku sosial sang anak akan terbentuk. Jenisjenis tingkah laku sosial pada anak ada berbagai macam, misalnya; agresi, mengejek, bersaing, membangkang, bertengkar \& berselisih, bekerja sama, merasa berkuasa, egois, dan simpati. (Suryana, 2016).

Goleman (dalam Yamin \& Sanan, 2010) mengungkapkan bahwa takut, bahagia, marah, cemas dan respon emosi yang lainnya adalah perbuatan represntasi atas kepuasan maupun ketidakpuasan anak terhadap sesuatu. Emosi tersebut bisa membantu sang anak untuk menentukan serta menjalankan apa yang menjadi tujuan dalam kehidupannya. Beliau juga mengatakan bahwa orang yang bisa mengendalikan serta mengontrol emosi yang mereka miliki secara efektif adalah orang yang cerdas.

Goode ( dalam Sari, 2018) menjelaskan bahwa emosi juga didefinisikan sebagai suatu hal yang sifatnya ilmiah yang terjadi karena adanya perkembangan atau pengalaman dari seseorang, perkembangan emosi jugadidasari dari halhal yang terjadi di lingkungan seseorang. Ketika ia sedang sendiri maupun sedang bersama dengan orang lain, anak mempelajari banyak hal, termasuk cara mengembangkan rasa percaya diri serta bagaimana ia bisa mengontrol dirinya sendiri. Beliau juga menambahkan bahwa anak mendapatkan ide-ide baru dalam menyelesaikan masalah yangmereka miliki dengan emosi yang mereka punya, sebab emosi merupakanaspek yang bisa dibilang penting baik itu emosi positif maupun emosi negatif.

Bersumber dari Susanto (2012), anakanak identik dengan ciri maupun karakteristik sosial emosional ialah; a) anak lebih suka bermain dengan teman sebayanya dibandingkan sendirian, b) mulai dapat mematuhi serta memahami peraturan dan berada pada tahap heteronomous morality, c) bisa membereskan mainannya, d) rasa penasaran yang besar, e) mulai bisa mengontrol emosinya, f) memiliki keinginan agar bisa berdiri sendiri. Suryana (2016) menyebutkan faktor-faktor perkembangan sosial emosional, yaitu; keluarga, kematangan, pendidikan, serta kapasitas mental.

Seorang psikolog asal Inggris bernama John Bowlby adalah orang pertama yang mengemukakan istilah attachment (kelekatan). Attachment memiliki arti suatu tingkal laku oleh seorang individu yang cenderung memiliki keinginan untuk mencari kedekekatan dengan individu lainnya seta mencari kepuasan dalam suatu hubungan dengan individu tersebut (Soetjaningsih, 2012). Pendapat lain mengatakan Attachment merupakan jalinan emosional bahwasannya bayi tumbuh dengan orang tua mereka, ikatan ini penting bagi mensejahterakan perkembangan sosial emosi pada anak (Oates, 2017).

Aspek-aspek secure attachment menurut Amrsden dan Greenberg (dalam Candra, dkk 2019) ialah; a) trust (kepercayaan), b) communication (komunikasi), c) alienation (pengasingan). Sedangkan faktor-faktornya yang dapat mempengaruhi secure attachment ialah; a) peran orang tua, b) komunikasi antara orang tua dan anak, c) konflik antar orang tua dan anak.

Fase-fase dalam menjalin secure attachment ada 4 fase, yaitu; a) Fase 1 (mulai dari lahir hingga usia 3 bulan): Respon yang beragam kepada orang lain, b) Fase 2 (usia 3 hingga 6 bulan): mulai fokus pada orang-orang yang ia kenali, c) Fase 3 (usia 6 bulan hingga 3 tahun): kelekatan yang intens serta pencrian kelekatan yang aktif, d) Fase 4 (usia 3 
tahun samppai akhir daripada masa anakanak).

Berdasarkan uraian permasalahan diatas, maka rumusan masalah pada penelitian ini ialah "Apakah ada atau tidaknya Hubungan Antara Secure Attachment Ibu Dan Anak Dengan Perkembangan Sosial Emosional Pada Anak Di RA Aisyah IT Pekanbaru?". Tujuan dari penelitian ini yaitu untuk mengetahui Hubungan antara secure attachment ibu dan anak dengan perkembangan sosial emosional pada anak di RA Aisyah IT Pekanbaru.

\section{METODE PENELITIAN}

Penelitian merupakan penelitian kuantitatif dengan pendekatan korelasional, ialahjenis yang dipakai guna melihat apakah ada ataupun tidak adanya hubungan antara variabel devendent dan variabel indevendent.

Variabel Devendent adalah Perkembangan sosial emosional anak dan Variabel indevendent adalah secure attachment (kelekatan aman). Sampel pada penelitian ini ialah seluruh wali murid (khusus ibu) di RA Aisyah IT Pekanbaru sejumlah 97 orang yang merupakan populasi wali murid (ibu) di RA Aisyah IT Pekanbaru. Dengan menggunakan Teknik sampling yang peneliti gunakan adalah purposive sample.

Metode pengumpulan data yang dilakukan penelitian adalah dengan melakukan penyebaran angket dengan menggunakan skala psikologi, skala secure attachment dan skala perkembangan sosial emosional anak . Dimana skala ini mempunyai tujuan yaitu untuk melihat bagaimana perkembangan sosial emosional anak berdasarkan hubungan kelekatannya dengan ibu.Penelitian yang digunakan adalah penelitian kuantitatif dan metode yang digunakan adalah metode analisis korelasi product moment

\begin{tabular}{ccc} 
HASIL DAN PEMBAHASAN & \\
Tabel 1 & \\
Hasil Uji & Normalitas \\
\hline Variabel & $\begin{array}{c}\text { Signifi } \\
\text { kansi }\end{array}$ & $\begin{array}{c}\text { Keteran } \\
\text { gan }\end{array}$ \\
\hline $\begin{array}{c}\text { Secure } \\
\text { Attachment }\end{array}$ & 0,153 & Normal \\
Perkembangan & 0,469 & Normal \\
Sosial & & \\
Emosional & & \\
\hline
\end{tabular}

Hasil uji normalitas dengan teknik one sampel kolmogrov-smirnov diatas menunjukkan bahwa variabel secure attachment dari ibu mempunyai persebaran data yang normal dengan signifikansi yaitu 0,153 $(p>0,05)$. Pada variabel perkembangan sosial emosional mempunyai persebaran data yang normal juga yaitu dengan signifikansi 0,469 $(p>0,05)$.

Tabel 2

Hasil Uji Normalitas

\begin{tabular}{lcccc}
\hline $\begin{array}{c}\text { Hubungan } \\
\text { Variabel }\end{array}$ & $\begin{array}{c}\text { Nilai } \\
\text { F }\end{array}$ & Sig & P & Ket. \\
\hline Hub. Secure & 1.922 & 0,086 & $P<0.05$ & Linier \\
Attachment & & & & \\
Dengan & & & \\
Perkembang & & & \\
an Sosial & & & & \\
Emosional. & & & & \\
\hline
\end{tabular}

Dari uji linearitas didapatkan hasil bahwa nilai devation from linearity untuk secure attachment dan perkembangan sosial emosional didapatkan bahwa nilai $\mathrm{F}$ (deviation) 1.922 dengan nilai $p=0,086$ $(p>0,05)$ sehingga dapat kita Tarik kesimpulan bahwa secure attachment dan perkembangan sosial emosional adalah linier. 
Tabel 3

Hasil Uji Hipotesis

\begin{tabular}{llcc}
\hline & & $\begin{array}{c}\text { Secure } \\
\text { Attachm } \\
\text { ent }\end{array}$ & $\begin{array}{c}\text { Perkemban } \\
\text { gan Sosial } \\
\text { Emosional }\end{array}$ \\
\hline Secure & $\begin{array}{l}\text { Pearson } \\
\text { Attachment }\end{array}$ & 1 & .332 \\
& $\begin{array}{l}\text { Correlati } \\
\text { on sig. } \\
\text { (2-tailed) }\end{array}$ & & .001 \\
\cline { 2 - 4 } & $\mathrm{N}$ & 97 & 97 \\
\hline $\begin{array}{l}\text { Perkembang } \\
\text { an Sosial }\end{array}$ & $\begin{array}{l}\text { Pearson } \\
\text { Correlati } \\
\text { Emosional }\end{array}$ & .332 & 1 \\
& $\begin{array}{l}\text { on Sig. } \\
\text { (2-tailed) }\end{array}$ & & \\
\cline { 2 - 4 } & $\mathrm{N}$ & 97 & 97 \\
\hline
\end{tabular}

Hipotesis pada penelitian ini ialah adanya hubungan yang positif diantara secure attachment dengan perkembangan sosial emosional pada anak di RA Aisyah IT Pekanbaru. Hasil yang didapatkan setelah dilakukan uji korelasi memakai terknik korelasi pearson product moment ialah nilai koefisien $(r)=0,332$ beserta signifikansi nilai $0,001 \quad(p<0.005)$ dimana hal ini menunjukkan hipotesis diterima yang artinya terdapat hubungan signifikan antara secure attachment dan perkembangan sosial emosional dengan arah yang positif. Dengan ini bisa dinyatakan bahwasannya semakin tinggi secure attachment ibu dan anak maka seakin tinggi pula perkembangan sosial emosional anak.

Sebelum anak mengetahui seperti apa dunia persekolahan. Lingkungan keluargalah yang pertama kali menjadi sarana untuk anak bersosialisasi. Namun ketika anak sudah mengenal lingkungan sekolah dan mulai bertemu orang yang dia anggap "asing", anak harus bisa menyesuaikan diri serta bersosialisasi dengan lingkungan yang baru ini. Hal ini sejalan dengan pada teori goalcoordinated partnership oleh Bowlby, dimana attachment akan menjadikan anak sebagai individu yang mempunyai hubungan sosial yang baik (Anapratiwi \& Handayani, 2013).

Yusuf (dalam Muamanah, 2018) mendefinisikan perkembangan sosial emosional sebagai perkembangan perilaku anak terhadap penyesuaian akan aturan yang ditegakkan dimanapun ia berada. Kemudian menurut Yamin dan Sunan perubahan perilaku terhadap orang sekitar, mencakup emosi serta sifat yang dikeluarkan adalah definisi dari perkembangan sosial emosional (Yamin \& Sunan, 2013).

Akmalia \& Rahayuningsih (2018) menyatakan bahwa anak akan mencapai tumbuh kembang yang optimal hanya ketika kebutuhan pokoknya dipenuhi, baik itu kebutuhan fisik (meliputi pakaian, makanan, dan tempat tinggal) serta psikis (bimbingan, kepedulian serta cinta).

Perkembangan sosial emosional bisa dipengaruhi oleh salah satunya secure attachment, seperti yang bisa kita lihat di hasil analisis korelasi yang sudah dilakukan didapatkan nilai $p=0,001$ $(p<0,005)$. Hal ini menunjukkan bahwa terdapat hubungan maupun korelasi yang signifikan antara secure attachment dengan perkembangan sosial emosional anak pada RA Aisyah IT Pekanbaru. Ainsworth berpendapat bahwa definisi dari attachment merupakan jalinan emosional yang dibangun oleh dua orang, dimana jalinan ini memiliki sifat khusus yaitu menjaga mereka agar tetap mempunyai keakraban satu sama lain dalam jangka waktu yang lama (Ervika, 2005).

Attachment membuat acuan kepada aspek ikatan dari orang tua terutama ibu sebagai figur lekat yang mendatangkan rasa nyaman, dilindungi, dijamin serta mendatangkan basic yang aman bagi anak agar dapat mengeksplor dunia lebih banyak lagi. Dimasa kanak-kanak, jalinan attachment ialah ikatan yang timbal baik yang artinya kedua pihak antara satu sama 
lain diuntungkan, dimana mereka saling memberi rasa kenyamanan (Santrock dalam Nurhayati, 2015).

Hal tersebut sejalan dengan hasil penelitian oleh Sulastri (2019) dengan variabel yang sama yaitu adanya hubungan secara signifikan antara kelekatananak dan ayahnya terhadap perkembangan sosial emosional dalam hubungan yang positif serta skor koefisien korelasi sebesar 0,416 . Begitu pula dengan hasil riset yang sudah dilakukan oleh Akmalia \& $R$ ahayuningsih (2018) dan dengan variabel yang sama bahwasannya adanya hubungan attachment ibu \& anak terhadap perkembangan sosial emosional pada bayi di wilayah kerja puskesmas Darul Imarah Kabupaten Aceh Besar.

Namun hal ini bertolak belakang dengan penelitian yang dilakukan oleh Sukarlinawati (2017) dimana hasil penelitiannya ialah dari 70 sampel, tingkat kelekatan anak balita dan orang tuanya mempunyai hubungan dengan perkembangan sosial anak balita namun tidak signifikan dengan nilai koefisien korelasi sebesar 0,071 pada taraf $99 \%$, yang berarti hanya $1 \%$ toleransi hubungan ke arah positif. Sedangkan pada kelekatan anak balita dan orang tuanya tidak mempunyai hubungan dengan perkembangan emosional anak balita dengan nilai koefisien sebesar $-0,090$ yang berarti tidak signifikan.

\section{SIMPULAN}

Menurut hasil penelitian yang telah dilakukan, maka kesimpulannya ialah terdapat hubungan antara secure attachment dengan perkembangan sosial emosional anak di RA Aisyah IT Pekanbaru. Adapun arah yang ditunjukkan dalam penelitian ini adalah perkembangan sosial emosionalmemiliki arah yang positif terhadap secure attachment yang artinya jika perkembangan sosial emosional tinggi maka secure attachment akan semakin tinggi pula.

\section{DAFTAR PUSTAKA}

Akmalia, I., \& Rahayuningsih, S. I. (2018). Attachment (Kelekatan) Ibu dan Anak dengan Perkembangan Sosial Emosional Bayi. Jurnal IImiah Mahasiswa Fakultas Keperawatan, 3(1)

Anapratiwi, D., \& Handayani, S. S. D. (2013). Hubungan antara kelekatan anak pada ibu dengan kemampuan sosialisasi anak usia 4-5 tahun (Studi pada RA Sinar Pelangi dan RA Al Iman Kecamatan Gunungpati, Semarang). Indonesian Journal of Early Childhood Education Studies, 2(2).

Arikunto, S. (2006). Prosedur Penelitian Suatu Pendekatan Praktik. Bandung: Rineka Cipta.

Azwar, S. (2011). Sikap dan Perilaku dalam: Sikap Manusia Teori dan Pengukurannya. Yogyakarta: Pustaka Pelajar.

Candra, I. (2019). Hubungan Antara Secure Attachment Dengan Kemandirian Pada Siswa Kelas Xi Sma/Ma Ar-Risalah Padang. Psyche 165 Journal, 12(2), 144-154.

CNN Indonesia. (2021, 9 Desember). KemenPPPA: Kasus Kekerasan Anak dan Perempuan Meningkat di 2021. [Online]. Tersedia di website: https://www.cnnindonesia.com/nasional/ 20211208195408-20-

731671/kemenpppa-kasus-kekerasananak-dan-perempuan-meningkat-di$\underline{2021}$

Ervika, E. (2005). Kelekatan (attachment) pada anak. Artikel. Fakultas Kedokteran: Universitas Sumatera Utara.

Eliasa, E. I. (2011). Pentingnya Kelekatan Orangtua Dalam Internal Working Model Untuk Pembentukan Karakter Anak (Kajian Berdasarkan Teori Kelekatan Dari John Bowlby). dalam Karakter sebagai Saripati Tumbuh Kembang Anak Usia Dini. Yogyakarta: Inti Media Yogyakarta Bekerjasama dengan Pusat Studi Pendidikan Anak Usia Dini 
Lembaga Penelitian Universitas Negeri Yogyakarta.

Hewi, L., Saleh, M., \& Wahyuni, R. (2019). Kelekatan (attachment) anak usia dini di Suku Laut Kabupaten Wakatobi. Jurnal Obsesi: Jurnal Pendidikan Anak Usia Dini, 4(1), 406-415.

Jahja, Y. (2011). Psikologi Perkembangan. Jakarta: Kencana

Kompas. (2020, 11 Desember). Setelah Guru Pesantren Perkosa Santriwati, 15 Siswi Dicabuli Guru Agama, Kenapa Pelecehan Seksual pada Anak Kian Marak?. [Online]. Tersedia di: https://www.kompas.com/sains/read/20 21/12/11/183100023/setelah-gurupesantren-perkosa-santriwati-15-siswidicabuli-guru-agama?page=all

Lubis, M. Y. (2019). Mengembangkan Sosial Emosional Anak Usia Dini Melalui Bermain. Generasi Emas: Jurnal Pendidikan Islam Anak Usia Dini, 2(1), 47-58.

Muamanah, S. (2019). Pengaruh Pola Asuh Orang Tuaterhadap Perkembangan Sosial Emosional Anak Usia 4-5 Tahun Di Desa Bandar Abung Kecamatan Abungsurakarta Kabupatenlampung Utara (Doctoral dissertation, UIN Raden Intan Lampung)

Mutiah, D. (2012). Psikologi Bermain Anak Usia Dini. Jakarta: Universitas Terbuka.

Nurhayati, H. (2015). Hubungan Kelekatan Aman (Secure Attachment) Anak Pada Orangtua Dengan Kemandirian Anak Kelompok B TK PKK 37 Dodongan Jatimulyo Dlingo Bantul (Skripsi). Universitas Negeri Yogyakarta.

Oates, M.W.J. (2015). Attachment Relationships. United Kingdom: Milton keynes
Sari, S. L., Devianti, R., \& NUR'AINI, S. A. F. I. T. R. I. (2018). Kelekatan Orangtua untuk Pembentukan untuk Pembentukan Karakter Anak. Educational Guidance and Counseling Development Journal, 1(1), 16-31

Soetjaningsih, C. H. (2012). Perkembangan Anak: Sejak Pembuahan Sampai dengan KanakKanak Akhir. Jakarta: Prenada Media Group.

Sugiyono. (2015). Metode Penelitian Penelitian Pendidikan (Pendidikan Kuantitatif, Kualitatif, dan R\&D). Banung: Alfabeta.

Sukarlinawati, W. (2017). Hubungan Antara Kelekatan Anak Balita Dan Orang Tuanyadengan Perkembangan Sosial, Emosional dan Kecerdasan. JURNAL PENDIDIKAN AGAMA, 8(2).

Sulastri, S. (2019). Hubungan Kelekatan Anak Perempuan Dengan Ayah Terhadap Perkembangan Sosial Emosional Anak Usia 4-6 Tahun Di Desa Pasar Pino Kec. Pino Raya Kab. Bengkulu Selatan (Doctoral dissertation, IAIN BENGKULU).

Suryana, D. (2016). Stimulus dan Aspek Perkembangan Anak. Jakarta: Kencana.

Susanto, A. (2012). Bina Karakter Anak Usia Dini. Yogyakarta: Geva Media.

Suyadi. (2010). Psikologi Belajar PAUD. Yogyakarta: Pusaka Abadi.

Yamin, M., dan Jamilah, S., S. (2010). Panduan Pendidikan Anak Usia Dini. Jambi: Gaung Persada. 